\title{
Large Copy-Number Variations in Patients With Statin-Associated Myopathy Affecting Statin Myopathy-Related Loci
}

\author{
V. STRÁNECKÝ ${ }^{1}$, M. NEŘOLDOVÁ ${ }^{2}$, K. HODAŇOVÁ ${ }^{1}$, H. HARTMANNOVÁ ${ }^{1}$, \\ L. PIHEROVÁ ${ }^{1}$, P. ZEMÁNKOVÁ ${ }^{5}$, A. PŘISTOUPILOVÁ ${ }^{1}$, M. VRABLÍK ${ }^{3}$, \\ V. ADÁMKOVÁ ${ }^{4}$, S. KMOCH ${ }^{1}$, M. JIRSA ${ }^{2}$
}

${ }^{1}$ Institute of Inherited Metabolic Disorders, First Faculty of Medicine, Charles University in Prague, Czech Republic, ${ }^{2}$ Laboratory of Experimental Hepatology, Institute for Clinical and Experimental Medicine, Prague, Czech Republic, ${ }^{3}$ Third Medical Department, First Faculty of Medicine, Charles University and General Faculty Hospital in Prague, Czech Republic, ${ }^{4}$ Preventive Cardiology

Department, Institute for Clinical and Experimental Medicine, Prague, Czech Republic, ${ }^{5}$ Institute of Biochemistry and Experimental Oncology, First Faculty of Medicine, Charles University in Prague, Czech Republic

Received December 23, 2015

Accepted April 29, 2016

On-line August 19, 2016

\section{Summary}

Some patients are susceptible to statin-associated myopathy (SAM) either because of genetic variations affecting statin uptake and metabolism, or because they predispose their carriers to muscular diseases. Among the frequent variants examined using the genome-wide association study approach, SLCO1B1 c.521T >C represents the only validated predictor of SAM in patients treated with high-dose simvastatin. Our aim was to ascertain the overall contribution of large copy-number variations (CNVs) to SAM diagnosed in 86 patients. CNVs were detected by whole genome genotyping using Illumina HumanOmni2.5 Exome BeadChips. Exome sequence data were used for validation of CNVs in SAM-related loci. In addition, we performed a specific search for CNVs in the SLCO1B region detected recently in Rotor syndrome subjects. Rare deletions possibly contributing to genetic predisposition to SAM were found in two patients: one removed EYS associated previously with SAM, the other was present in $\angle A R G E$ associated with congenital muscular dystrophy. Another two patients carried deletions in CYP2C19, which may predispose to clopidogrel-statin interactions. We found no common large CNVs potentially associated with SAM and no CNVs in the SLCO1B locus. Our findings suggest that large CNVS do not play a substantial role in the etiology of SAM.

\section{Key words}

Statin myopathy $\bullet$ Copy number variations $\bullet S L C O 1 B$

\section{Corresponding author}

M. Jirsa, Institute for Clinical and Experimental Medicine, Building Z1, Vídeňská 1958/9, 14021 Prague 4 - Krč, Czech Republic. E-mail: miji@ikem.cz

\section{Introduction}

Statins acting as HMG-CoA inhibitors decrease total serum and LDL-cholesterol and reduce the risk of ischemic heart disease. Although statins are generally well tolerated, a significant number of patients suffer from various side effects, including muscle pain and weakness. Myalgia without elevated serum creatine kinase (CK) activity and myopathy with elevated serum $\mathrm{CK}$ represent the most frequent causes of statin intolerance (Argov 2015). Although very rare, rhabdomyolysis is the most severe form of myopathy and results in muscle breakdown, myoglobinuria, kidney damage and death (Van Staa et al. 2014). The frequency of muscle problems increases with the daily dose of statins (Mosshammer et al. 2014). The mechanisms contributing to statin-associated myopathy (SAM) 
include decreased cholesterol content in muscle cell membranes, decreased production of ubiquinone, decreased prenylation of proteins, increased uptake of cholesterol and plant sterols, impaired metabolism of calcium and decreased production of selenoproteins (Mammen and Amato 2010, Thompson et al. 2003, Ucar et al. 2000). Moreover, administration of statins may unmask pre-existing myopathy due to heterozygous carrier status for muscle disease causing mutation (Argov 2015).

Family studies suggest the involvement of a strong genetic component in statin-induced muscle toxicity and susceptibility (Hedenmalm et al. 2015). Genetic factors predisposing carriers to SAM (Ghatak et al. 2010, Mosshammer et al. 2014) are divided into several groups - factors affecting 1) blood concentration of statins (variations in genes encoding transporters OATP1B1, OATP1B3, OATP2B1, ABCB1, ABCG2 and enzymes CYP3A4, CYP3A5, CYP2C8, CYP2D6, CYP2D9, CYP1A2, CYP2E1, CYP2A6 and CYP2B6), 2) muscle vascularisation (genes encoding angiotensin receptor 1 (AGTR1) and NOS3 and 3) concentration of statins in muscle cells (genes encoding transporters OATP2B1, MRP1, MRP4 and MRP5). Additional numerous factors play a role in the etiology of primary muscle diseases, classified as 4) rare variants underlying disorders of muscle cell energy metabolism in genes encoding myophosphorylase (PYGM), alpha-glucosidase (Stroes et al. 2015), carnitine palmitoyltransferase 2 (CPT2) and myoadenylate deaminase (AMPD1), 5) variants responsible for mitochondrial myopathies, 6) variants affecting production of coenzyme Q10 (genes COQ10A and COQ10B), 7) variants associated with muscle dystrophy (genes encoding dystrophin $(D M D)$, myotilin (MYOT), lamin A/C (LMNA) and caveolin-3 $(C A V 3))$ and 8) factors affecting calcium homeostasis (genes encoding the ryanodine receptor 1 (RYR1), $\mathrm{Na}^{+} / \mathrm{K}^{+}$-ATPase (ATP1A1, ATP1A2, ATP1B1, ATP1G1) and $\mathrm{Ca}^{2+}$-ATPase $\left.(A T P 2 A 1)\right)$.

Common genetic variations do not seem to be important determinants of statin-induced muscle toxicity (Hopewell et al. 2014), with one exception: the SLCO1B1 rs4149056 genotype (Link et al. 2008). In this study we focused on the potential contribution of large rare copy number variants (CNVs) affecting the abovementioned candidate genes and/or genes involved in functionally related metabolic pathways. Moreover, since SLCO1B1 c.521T $>$ C (p.V174A) rs4149056 decreases liver uptake of hydrophilic statins and given that allele
c.521C is associated with high-dose simvastatin (as found in the SEARCH Collaborative Study (Link et al. 2008)), we chose to examine our patients for the presence of known small deletions (Van De Steeg et al. 2012) and insertions (Kagawa et al. 2015) in the SLCO1B locus on chromosome $12 p$, found previously in patients with Rotor syndrome.

\section{Methods}

\section{Selection of study subjects}

Eighty-six patients treated with simva-, atorva- or rosuvastatin for familial or polygenic hypercholesterolemia and suffering from SAM fulfilling the consensual definition of the American College of Cardiology (ACC)/ American Heart Association (AHA) / National Heart, Lung and Blood Institute (NHLBI) (Pasternak et al. 2002) were enrolled. None of the patients was administered the known inhibitors of SLCO1B1/OATP1B1 - cyclosporine, rifampicin, antibiotics, anticancer drugs, estrogens, oral contraceptives - for at least one month prior to the onset of myopathy. Secondary causes of myopathy (e.g. hypothyroidism and other endocrine diseases, alcohol abuse, drug-induced) were excluded. Pregnancy was ruled out in fertile women. Consecutive patients who developed SAM over the course of the four-year study were included.

Written informed consent was obtained from all the study participants prior to any study-related procedure. The local ethics committee approved the conduct of the study, respecting the rules of the Declaration of Helsinki of 1975.

\section{DNA genotyping and CNV identification}

Genomic DNA of all available individuals was extracted from whole blood samples using the Qiagen DNA micro kit (QIAgen, Hilden, Germany). The quantity and quality of the isolated DNA were verified spectrophotometrically using the NanoDrop 2000 (Thermo Fisher Scientific, Prague, Czech Republic). Genotyping was performed using Illumina HumanOmni2.5 Exome BeadChips (San Diego, CA) at The Microarray Facility of The Centre of Applied Genomics of The Hospital for Sick Children in Toronto according to manufacturer protocol. Raw data were uploaded into Illumina GenomeStudio version 2011.1 for genotype calling. All samples with a genotype call rate $>99 \%$ were subjected to further analysis. Relatedness of 
investigated subjects was assessed from obtained genotypes in PLINK (Purcell et al. 2007).

Extended homozygosity regions $>3 \mathrm{Mb}$ were detected using the 3.2.0 Illumina cnvPartition CNV Analysis Plug-in within GenomeStudio software.

CNVs were identified using PennCNV (Wang et al. 2007) and the above-mentioned cnvPartition CNV Analysis Plug-in. Only gains and losses containing a minimum of 10 probes were reported. Gene content of CNVs of interest was functionally annotated in GeneDistiller (Seelow et al. 2008) and population frequencies of the identified changes were assessed in the curated catalogue of human genomic structural variations known as DGV (http://dgv.tcag.ca/dgv/app/home).

\section{Validation of identified $C N V S$}

The existence of selected CNVs was independently assessed in exome sequence data, which were made available for each of the samples. DNA for exome sequencing was enriched using SeqCap V3 (NimbleGen) and sequenced on the Illumina HiSeq 1500 system at the University Hospital in Motol (Prague, Czech Republic) as previously described (Kmoch et al. 2015).

The resulting FASTQ files were aligned to the human genome reference (hg19) using NovoAlign (Novocraft Technologies, Selangor, Malaysia). Following genome alignment, conversion of SAM format to BAM and duplicate removal were performed using Picard Tools v.1.129 (http://broadinstitute.github.io/picard/). The Genome Analysis Toolkit (GATK) (3.3) was used for local realignment around indels, base recalibration, variant recalibration and genotyping. CNVs were identified from exome read counts using CONTRA 2.0.6 (Li et al. 2012) and CNVkit 0.74 (Talevich et al. 2014).

Detection of deletions in the SLCO1B locus found previously in subjects with Rotor syndrome

The $405 \mathrm{~kb}$ deletion NCBI37/hg19 g.(21,007,644)_(21,412,242)del(CA)ins, removing exons 3-15 of SLCO1B3 and the whole gene SLCO1B1, and the $7.2 \mathrm{~kb}$ deletion NCBI37/hg19 chr12:g.(21,035,810)_(21,043,025)del(N205)ins removing SLCO1B3 exon 12 were genotyped as described by Van De Steeg et al. (2012). The heterozygous state for the $7.2 \mathrm{~kb}$ deletion was confirmed by simultaneous amplification of the deleted allele and the SLCO1B3 exon 12 present in the non-deleted allele. We also screened patients for the presence of recently reported long interspersed element-1 (LINE-1) in intron 5 of SLCO1B3 (Kagawa et al. 2015). For this purpose, we used the PCR-based technique reported by Kagawa et al. (2015). Blood DNA samples taken from Rotor subjects homozygous for each of the tested mutations and from their heterozygous parents served as positive controls.

\section{Results}

\section{Clinical and laboratory findings}

Eighty-six patients ( 30 males and 56 females) aged 29 to 84 years (median - 65 years, interquartile range -7 years) were selected from patient databases comprising approximately 2500 patients treated for dyslipidemia at the lipid clinics of the $3^{\text {rd }}$ Department of Medicine, $1^{\text {st }}$ Medical Faculty of Charles University and of the Institute for Clinical and Experimental Medicine in Prague. Of these, 51 patients developed myopathy on atorvastatin on a daily dose of $10-20 \mathrm{mg}$ (only 2 patients were given $40 \mathrm{mg}$ daily), 20 patients developed muscle symptoms on simvastatin (daily dose 20-40 mg) and 12 patients on rosuvastatin (daily dose 10-20 mg, 2 patients were given $40 \mathrm{mg}$ daily). One patient presented with muscle symptoms repeatedly on both atorvastatin and rosuvastatin and 2 patients complained while using simva-, atorva- and rosuvastatin.

Fifty-four patients (22 males and 32 females) met the recently published criteria (Vrablik et al. 2014) for definitive diagnosis of SAM, whereas in the remaining 32 patients ( 8 males and 24 females) myopathy was classified as possible.

The median time between the onset of statin therapy and myopathy, calculated from the data obtained from 78 patients, was 1 month. Later onset of myopathy was recorded between month 4 and month 10 only in 10 patients.

Treatment was temporarily interrupted in all examined patients. The median interval between statin withdrawal and myopathy remission, calculated from the data provided by 71 patients, was 10 days with a maximum of 30 days. No remission was achieved in two patients.

All 58 patients in whom serum activity of CK was measured before statin administration, at the onset of muscle problems and after their cessation, reached the highest CK activity at the onset of the myopathy. However, in 9 patients the peak activity of CK did not exceed the upper normal limit. Serum CK activity was not measured in 28 patients (Table 1). Most patients with 
severe CK elevation $>20 \mu \mathrm{kat} / 1$ also had a concomitant elevation in serum activity of aspartate aminotransferase (AST). In contrast, none of the patients with CK activity
$<20 \mu \mathrm{kat} / 1$ had serum AST activity higher than twice the normal level.

Table 1. Clinical and laboratory findings in enrolled patients with statin-induced myopathy grouped according to their serum CK activity levels.

\begin{tabular}{|c|c|c|c|c|c|c|c|}
\hline $\begin{array}{l}\text { Serum CK } \\
\text { activity }\end{array}$ & $\begin{array}{c}\text { No. of } \\
\text { patients }\end{array}$ & $\begin{array}{l}\text { Sex } \\
(\mathbf{m} / \mathbf{f})\end{array}$ & $\begin{array}{l}\text { Median age } \\
\text { (IQR) }\end{array}$ & $\begin{array}{c}\text { Susp/proven } \\
\text { diagnosis }\end{array}$ & $\begin{array}{c}\text { Atorva/ } \\
\text { Simva/ } \\
\text { Rosuva } \\
(\%)\end{array}$ & $\begin{array}{c}\text { Fibrate } \\
\text { users }\end{array}$ & SAM type \\
\hline$>5 \mathrm{x}$ ULN & 12 & $10 / 2$ & $60(53-66)$ & $\begin{array}{l}6 \text { suspect } \mathrm{hFH} \text {, } \\
\text { all } 12 \text { polygenic }\end{array}$ & $50 / 25 / 25$ & $4(33 \%)$ & $\begin{array}{c}11(92 \%) \text { defin } \\
1(8 \%) \text { prob }\end{array}$ \\
\hline $1-5 x$ ULN & 37 & $13 / 24$ & $67(60-71)$ & $\begin{array}{c}4 \text { suspect } \mathrm{hFH} \\
2 \mathrm{hFH} \text { proven } \\
35 \text { polygenic }\end{array}$ & $62 / 25 / 13$ & $7(19 \%)$ & $\begin{array}{l}25(68 \%) \text { defin } \\
12(32 \%) \text { prob }\end{array}$ \\
\hline$<\mathrm{ULN}$ & 9 & $3 / 6$ & $67(58-70)$ & $\begin{array}{c}4 \text { suspect } \mathrm{hFH} \\
1 \mathrm{hFH} \text { proven } \\
8 \text { polygenic }\end{array}$ & $78 / 11 / 11$ & $2(22 \%)$ & $\begin{array}{l}6(67 \%) \text { defin } \\
3(33 \%) \text { prob }\end{array}$ \\
\hline not available & 28 & $4 / 24$ & $63(58-68)$ & $\begin{array}{l}3 \text { suspect } \mathrm{hFH} \text {, } \\
\text { all } 28 \text { polygenic }\end{array}$ & $50 / 25 / 25$ & $6(21 \%)$ & $\begin{array}{l}12(43 \%) \text { defin } \\
16(57 \%) \text { prob }\end{array}$ \\
\hline
\end{tabular}

ULN - upper limit of normal, IQR - interquartile range, hFH - heterozygous familial hypercholesterolemia, defin - definitive, prob - probable.

Table 2. Rare large deletions leading to heterozygous losses in genes potentially involved in SAM pathogenesis and in clopidogrel-statin interactions.

\begin{tabular}{lcccc}
\hline Patient no. & 28 & 30 & 41 & 47 \\
Chromosome no. & 10 & 6 & 10 & 22 \\
Begin (GRCh37/hg19) & 96443782 & 65786994 & 96499710 & 34265402 \\
End (GRCh37/hg19) & 96620554 & 65815520 & 96557336 & 34271782 \\
Size (bp) & 176772 & 28526 & 57626 & 6380 \\
Gene name & CYP2C18, CYP2C19 & EYS & CYP2C19 & LARGE \\
${ }^{*}$ DGV gold std var. frequency (\%) & 0.9 & 0.3 & 3.0 & 0.1 \\
Potential functional implication & clopidogrel-statin & SAM? & clopidogrel-statin & interaction \\
& interaction & & SAM? \\
\hline
\end{tabular}

${ }^{*}$ DGV - catalogue of human genomic structural variation.

CNV analysis

DNA genotyping was performed in all 86 subjects. All analyzed samples passed the set genotyping criteria, although one sample had to be excluded from further analysis due to the detection of an abnormally high number of CNVs. Genotype analysis confirmed that all study subjects were genetically unrelated.

In the remaining 85 subjects, we identified a total of 2552 CNVs: 684 losses and 1868 gains. In this set, we searched for CNVs that were longer than $20 \mathrm{~kb}$ and located within $\pm 50 \mathrm{~kb}$ of any established gene loci. This analysis retrieved 503 CNVs: 164 losses and 339 gains.

The 164 losses ranging from $20-892 \mathrm{~kb}$ were present in 76 subjects. From these losses, 27 were recurrent (i.e. found repeatedly in the patient cohort) and 58 were singletons. The losses affected 205 distinct gene 
loci, from which 156 loci were functionally annotated in GeneDistiller (http://www.genedistiller.org/). Among these annotated gene loci, we searched using selected key words for the candidate genes listed in the introduction and the following genes: an additional 10 genes for nemaline myopathy (North and Ryan 2015); 7 genes for centronuclear/core myopathies (BIN1, CCDC78, CNTN1, DNM2, MTM1, MYF6, MYH7); 12 genes for congenital muscular dystrophies (Sparks et al. 2012); 6 genes underlying the congenital myopathies with prominent contractures (EMD, FHL1, SEPN1, SYNE1, SYNE2, TMEM43); 16 genes for limb-girdle muscular dystrophies (Pegoraro and Hoffman 2012); 12 genes for congenital myasthenic syndromes (Abicht et al. 2012) and 24 genes associated with metabolic myopathies (ACADL, ACADM, ACADVL, ACAD9, AGL, C10orf2, CPT1B, GYS1, HADHA, HADHB, LPIN1, OPA1, OPA3, PFKM, PGAM2, PGM1, PHKA1, POLG, POLG2, RRM2B, SLC22A5/OCTN2, SUCLA2, TK2, TYMP). Moreover, we also considered published associations for each of the 156 annotated genes with myopathy or statin metabolism and their potential involvement in pathways reviewed in Ghatak et al. (2010) and Mosshammer et al. (2014). Using this approach we defined four singleton candidate deletions, which were confirmed from the exome sequence data (Table 2).

Gains ranging from $20-522 \mathrm{~kb}$ were present in 83 subjects. From the 339 identified gains, 41 were recurrent and 115 were singletons. The gains affected 359 distinct gene loci, from which 271 loci were functionally annotated in GeneDistiller and evaluated as above. Among the annotated gains we found no single candidate amplification that was independently confirmed in the exome sequence data.

Targeted genotyping for known Rotor syndrome deletions and insertions affecting SLCO1B1 and $S L C O 1 B 3$ was performed in all 86 studied individuals. None of the investigated patients carried any of these three tested candidate variants.

\section{Discussion}

Biological mechanisms and genetic factors contributing to SAM are heterogeneous and remain enigmatic. Previous genetic studies have focused almost exclusively on the role of common genetic variants, mostly single nucleotide polymorphisms, and have identified only a small fraction of the expected heritability (Feng 2014, Vrablik et al. 2014).
Copy number variations constitute a substantial fraction of the total genetic variability known to cause, predispose to, and modulate, human diseases (Zarrei et al. 2015). The distribution of larger CNVs in the general population remains largely unexplored. Because rare pathogenic copy number variations are often large and contain multiple genes, identification of the underlying genetic drivers has proven difficult. In our analysis, we searched for recurrent or individually rare CNVs that may affect genes involved in drug metabolism and muscle function. We did not find any cases of recurring CNVs that would be present in higher frequencies when compared to the general population reported in the curated catalogue of human genomic structural variation (DGV) and in our internal database. Our findings thus suggest that in addition to common single nucleotide variants, large CNVs do not seem to play a substantial role in the etiology of SAM.

In two studied cases, a rare $\mathrm{CNV}$ that could be considered an individually contributing genetic factor was detected. In one patient, we found a $28 \mathrm{~kb}$ deletion in intron 12 of $E Y S$ which may have impaired its splicing pattern. Common variants in EYS were found to be associated with SAM in a large study based on the GWAS approach (Isackson et al. 2011). However, this finding has not been validated in further studies.

A $6.4 \mathrm{~kb}$ deletion located in intron 1 of $L A R G E$ was detected in the other patient. Pathogenic mutations in $L A R G E$, when present on both alleles, are known to cause autosomal recessive dystroglycanopathy, which is considered a subtype of congenital muscular dystrophy. Interestingly, a large intronic deletion in exon 10 of $L A R G E$ has recently been identified as causing the disease in a consanguineous family from Lebanon (Clarke et al. 2011).

In another two patients, we found $176 \mathrm{~kb}$ and $57 \mathrm{~kb}$ deletions affecting the CYP2C18/CYP2C19 locus. While one patient completely lacked both CYP2C18 and CYP2C19, the smaller deletion present in the other patient removed only the first five exons of CYP2C19. CYP2C19 is known to metabolize a significant number of drugs except for statins (Hirota et al. 2013). However, haploinsufficiency of $C Y P 2 C 19$ contributes to the altered metabolism of clopidogrel concomitantly used with atorvastatin (Tantry et al. 2014).

In conclusion, our findings suggest that the participation of common large CNVs in genetic predisposition to SAM is unlikely, whereas rare CNVs may play some role in SAM pathogenesis. 


\section{Conflict of Interest}

There is no conflict of interest.

\section{Acknowledgements}

The study was supported by grant no. NT-14025-3/2013 from the Internal Grant Agency of the Ministry of Health of the Czech Republic. We wish to thank the Genomic Facility at Motol University Hospital in Prague (OPPK.CZ.2.16/3.100/24022) and The National Centre for Medical Genomics (LM2015091) for their instrumental and technical support with genotyping and WES analyses.

\section{References}

ABICHT A, MULLER JS, LOCHMULLER H: Congenital myasthenic syndromes. In: GeneReviews. PAGON RA, ADAM MP, ARDINGER HH, WALLACE SE, AMEMIYA A, BEAN LJH, BIRD TD, LEDBETTER N, MEFFORD HC, SMITH RJC, STEPHENS K (eds), University of Washington, Seattle (WA), updated 2012.

ARGOV Z: Statins and the neuromuscular system: a neurologist's perspective. Eur J Neurol 22: 31-36, 2015.

CLARKE NF, MAUGENRE S, VANDEBROUCK A, URTIZBEREA JA, WILLER T, PEAT RA, GRAY F, BOUCHET C, MANYA H, VUILLAUMIER-BARROT S, ENDO T, CHOUERY E, CAMPBELL KP, MEGARBANE A, GUICHENEY P: Congenital muscular dystrophy type 1D (MDC1D) due to a large intragenic insertion/deletion, involving intron 10 of the LARGE gene. Eur J Hum Genet 19: 452-457, 2011.

FENG Q: Approach to clinical and genetic characterization of statin-induced myopathy. Methods Mol Biol 1175: 67-90, 2014.

GHATAK A, FAHEEM O, THOMPSON PD: The genetics of statin-induced myopathy. Atherosclerosis 210: 337-343, 2010.

HEDENMALM K, GRANBERG AG, DAHL ML: Statin-induced muscle toxicity and susceptibility to malignant hyperthermia and other muscle diseases: a population-based case-control study including 1st and 2nd degree relatives. Eur J Clin Pharmacol 71: 117-124, 2015.

HIROTA T, EGUCHI S, IEIRI I: Impact of genetic polymorphisms in CYP2C9 and CYP2C19 on the pharmacokinetics of clinically used drugs. Drug Metab Pharmacokinet 28: 28-37, 2013.

HOPEWELL JC, REITH C, ARMITAGE J: Pharmacogenomics of statin therapy: any new insights in efficacy or safety? Curr Opin Lipidol 25: 438-445, 2014.

ISACKSON PJ, OCHS-BALCOM HM, MA C, HARLEY JB, PELTIER W, TARNOPOLSKY M, SRIPATHI N, WORTMANN RL, SIMMONS Z, WILSON JD, SMITH SA, BARBOI A, FINE E, BAER A, BAKER S, KAUFMAN K, COBB B, KILPATRICK JR, VLADUTIU GD: Association of common variants in the human eyes shut ortholog (EYS) with statin-induced myopathy: evidence for additional functions of EYS. Muscle Nerve 44: 531-538, 2011.

KAGAWA T, OKA A, KOBAYASHI Y, HIASA Y, KITAMURA T, SAKUGAWA H, ADACHI Y, ANZAI K, TSURUYA K, ARASE Y, HIROSE S, SHIRAISHI K, SHIINA T, SATO T, WANG T, TANAKA M, HAYASHI H, KAWABE N, ROBINSON PN, ZEMOJTEL T, MINE T: Recessive inheritance of populationspecific intronic LINE-1 insertion causes a rotor syndrome phenotype. Hum Mutat 36: 327-332, 2015.

KMOCH S, MAJEWSKI J, RAMAMURTHY V, CAO S, FAHIMINIYA S, REN H, MACDONALD IM, LOPEZ I, SUN V, KESER V, KHAN A, STRANECKY V, HARTMANNOVA H, PRISTOUPILOVA A, HODANOVA K, PIHEROVA L, KUCHAR L, BAXOVA A, CHEN R, BARSOTTINI OG, PYLE A, GRIFFIN H, SPLITT M, SALLUM J, TOLMIE JL, SAMPSON JR, CHINNERY P, BANIN E, SHARON D, DUTTA S, GREBLER R, HELFRICH-FOERSTER C, PEDROSO JL, KRETZSCHMAR D, CAYOUETTE M, KOENEKOOP RK: Mutations in PNPLA6 are linked to photoreceptor degeneration and various forms of childhood blindness. Nat Commun 6: 5614, 2015.

LI J, LUPAT R, AMARASINGHE KC, THOMPSON ER, DOYLE MA, RYLAND GL, TOTHILL RW, HALGAMUGE SK, CAMPBELL IG, GORRINGE KL: CONTRA: copy number analysis for targeted resequencing. Bioinformatics 28: 1307-1313, 2012.

LINK E, PARISH S, ARMITAGE J, BOWMAN L, HEATH S, MATSUDA F, GUT I, LATHROP M, COLLINS R: SLCO1B1 variants and statin-induced myopathy--a genomewide study. $N$ Engl J Med 359: 789-799, 2008. 
MAMMEN AL, AMATO AA: Statin myopathy: a review of recent progress. Curr Opin Rheumatol 22: 644-650, 2010.

MOSSHAMMER D, SCHAEFFELER E, SCHWAB M, MORIKE K: Mechanisms and assessment of statin-related muscular adverse effects. Br J Clin Pharmacol 78: 454-66, 2014.

NORTH KN, RYAN MN: Nemaline myopathy. In: GeneReviews. PAGON RA, ADAM MP, ARDINGER HH, WALLACE SE, AMEMIYA A, BEAN LJH, BIRD TD, LEDBETTER N, MEFFORD HC, SMITH RJC, STEPHENS K (eds), University of Washington, Seattle (WA), updated 2015.

PASTERNAK RC, SMITH SC JR, BAIREY-MERZ CN, GRUNDY SM, CLEEMAN JI, LENFANT C: ACC/AHA/NHLBI clinical advisory on the use and safety of statins. Stroke 33: 2337-2341, 2002.

PEGORARO E, HOFFMAN EP: Limb-girdle muscular dystrophy overview. In: GeneReviews. PAGON RA, ADAM MP, ARDINGER HH, WALLACE SE, AMEMIYA A, BEAN LJH, BIRD TD, LEDBETTER N, MEFFORD HC, SMITH RJC, STEPHENS K (eds), University of Washington, Seattle (WA), updated 2012.

PURCELL S, NEALE B, TODD-BROWN K, THOMAS L, FERREIRA MA, BENDER D, MALLER J, SKLAR P, DE BAKKER PI, DALY MJ, SHAM PC: PLINK: a tool set for whole-genome association and populationbased linkage analyses. Am J Hum Genet 81: 559-575, 2007.

SEELOW D, SCHWARZ JM, SCHUELKE M: GeneDistiller--distilling candidate genes from linkage intervals. PLoS One 3: e3874, 2008.

SPARKS S, QUIJANO-ROY S, HARPER A, RUTOWSKI A, GORDON E, HOFFMAN EP, PEGORARO E: Congenital muscular dystrophy overview. In: GeneReviews. PAGON RA, ADAM MP, ARDINGER HH, WALLACE SE, AMEMIYA A, BEAN LJH, BIRD TD, LEDBETTER N, MEFFORD HC, SMITH RJC, STEPHENS K (eds), University of Washington, Seattle (WA), updated 2012.

STROES ES, THOMPSON PD, CORSINI A, VLADUTIU GD, RAAL FJ, RAY KK, RODEN M, STEIN E, TOKGOZOGLU L, NORDESTGAARD BG, BRUCKERT E, DE BACKER G, KRAUSS RM, LAUFS U, SANTOS RD, HEGELE RA, HOVINGH GK, LEITER LA, MACH F, MARZ W, NEWMAN CB, WIKLUND O, JACOBSON TA, CATAPANO AL, CHAPMAN MJ, GINSBERG HN: Statin-associated muscle symptoms: impact on statin therapy - European Atherosclerosis Society Consensus Panel Statement on Assessment, Aetiology and Management. Eur Heart J 36: 1012-1022, 2015.

TALEVICH E, SHAIN AH, BOTTON T, BASTIAN BC: CNVkit: copy number detection and visualization for targeted sequencing using off-target reads. bioRxiv 010876, 2014. doi: http://dx.doi.org/10.1101/010876

TANTRY US, JEONG YH, GURBEL PA: The clopidogrel-statin interaction. Circ J 78: 592-594, 2014.

THOMPSON PD, CLARKSON P, KARAS RH: Statin-associated myopathy. JAMA 289: 1681-1690, 2003.

UCAR M, MJORNDAL T, DAHLQVIST R: HMG-CoA reductase inhibitors and myotoxicity. Drug Saf 22: 441-457, 2000.

VAN DE STEEG E, STRANECKY V, HARTMANNOVA H, NOSKOVA L, HREBICEK M, WAGENAAR E, VAN ESCH A, DE WAART DR, OUDE ELFERINK RP, KENWORTHY KE, STICOVA E, AL-EDREESI M, KNISELY AS, KMOCH S, JIRSA M, SCHINKEL AH: Complete OATP1B1 and OATP1B3 deficiency causes human Rotor syndrome by interrupting conjugated bilirubin reuptake into the liver. $J$ Clin Invest 122: 519-528, 2012.

VAN STAA TP, CARR DF, O'MEARA H, MCCANN G, PIRMOHAMED M: Predictors and outcomes of increases in creatine phosphokinase concentrations or rhabdomyolysis risk during statin treatment. Br J Clin Pharmacol 78: 649-659, 2014.

VRABLIK M, ZLATOHLAVEK L, STULC T, ADAMKOVA V, PRUSIKOVA M, SCHWARZOVA L, HUBACEK JA, CESKA R: Statin-associated myopathy: from genetic predisposition to clinical management. Physiol Res 63 (Suppl 3): S327-S334, 2014.

WANG K, LI M, HADLEY D, LIU R, GLESSNER J, GRANT SF, HAKONARSON H, BUCAN M: PennCNV: an integrated hidden Markov model designed for high-resolution copy number variation detection in wholegenome SNP genotyping data. Genome Res 17: 1665-1674, 2007.

ZARREI M, MACDONALD JR, MERICO D, SCHERER SW: A copy number variation map of the human genome. Nat Rev Genet 16: 172-183, 2015. 